\title{
An Application of PLAR in the Development of the Aboriginal Self: One College's Experience
}

\author{
Lloyd Hawkeye Robertson
}

Northlands College, Canada

\section{Abstract}

Some forms of prior learning assessment and recognition (PLAR) invite self-reflection and the generation of new knowledge leading to self-growth in granting credit for past experiential learning. This paper examines the experience of a northern Canadian community college using PLAR portfolio development to assist in individual self-growth among people of aboriginal ancestry. The author reviews the theoretical underpinning behind the notion that PLAR may be used in identity construction and reviews some of the historical circumstances affecting the development of aboriginal selves. Divergent views of participants who had completed PLAR facilitator training on portfolio development are examined. Ethical concerns are raised, and guidelines are proposed for the use of PLAR in portfolio development and identity construction.

Keywords: Self; self-development; aboriginal identity; PLAR

A distinctive feature of prior learning assessment and recognition (PLAR) has been its use of qualitative methods in assessing learning in adults (Amichand, Ireland, Orynik, Potter, \& Van Kleef, 2007; Conrad, 2008; Van Kleef, 2007). While quantitative methods are also used, some experiential learning cannot be quantified. Demonstrations, testimonials, records, or other media may be combined with narratives to build portfolios outlining life experiences and the learning that resulted from those experiences. The process of reflecting such experiences may generate new understandings and hence new knowledge (Conrad, 2008). Such knowledge creation has implications for self-development.

In 2001 Northlands College, situated in northern Canada and serving a largely (80\%) aboriginal population, began training staff in a form of PLAR that emphasizes aboriginal cultural content and personal self-growth. This was initially introduced to Northlands as "An aboriginal perspective on PLAR and portfolio development” (Hill, 2004), but subsequent 
proposals to the college by prospective PLAR facilitators have titled the training Holistic Portfolio PLAR, in keeping with similar training offered elsewhere (Morrissey \& Myers, 2008). The term holistic references the objective of identifying all major life experiences and not just those directly related to employment and educational objectives. The emphasis, in this approach, becomes one of self-understanding and self-development.

In 2008, some Northlands College PLAR trainees expressed concern that they did not have the professional training to deal with emotional catharsis resulting from student activity in preparing their holistic portfolios. Further, they felt they were expected to promote native spirituality, which some identified as a religion. Issues of emotional catharsis and religious conversion are not immediately identified with the assessment of prior learning, and such concerns invite investigation.

This paper examines the process of self-transformation, including support for the notion that such transformation may involve emotional catharsis. The author then examines an historical model for understanding how colonialism on the American continents impacted psychologically on its aboriginal inhabitants and how that model could be applied in the context of PLAR portfolio development. Also examined are the responses of people who received training in a form of aboriginal holistic portfolio PLAR over a four-year period for indicators that their perceived experience matches this self-transformative historic trauma model. Finally, there is a discussion of ethical and procedural issues informing the practice of using portfolio PLAR in an aboriginal context.

\section{Learning as Self-Transformation}

Van Kleef (2007) noted that experience does not necessarily result in learning, and to learn from experience one must have the capacity to reflect on that experience. She quoted Knowles (1970) as stating that adults and their experiences are so intertwined that "an adult is what he has done.... When an adult is in a situation in which his experience is not being used, or its worth is minimized, it is not just his experience that is being rejected - he feels rejected as a person" (p. 44). From this understanding, she interpolated:

In the model proposed in this paper, the act of reflection is a fundamental component of PLAR and can be used by learners before, during, and following the assessment process to consider the nature of their prior learning in relation to themselves and educators' expected outcomes. (p. 7)

Van Kleef (2007) viewed assessment techniques such as reflective journaling, case studies, critical incident reflection, role playing, and self-reflective portfolio development as powerful techniques that give learners an opportunity to gain new meaning from their own experiences. Conrad (2008) agreed that learners construct their own knowledge from their experiences, and she said Athabasca University uses both challenge-for-credit and portfolio development methods of assessing prior experience. She explained that while under 
the challenge-for-credit policy learners match their prior learning to the knowledge base and skill requirements of specific courses, portfolio development "gives rise to new knowledge-of self, of self situated within the trajectory of growth, and of self situated within the profession" (p. 142). Thus, the process of new knowledge construction using portfolio development is part of the process of identity construction. Robertson (2010) supported the notion that although our selves evolve through time, we need a sense of self-stability to effectively relate to others and engage in forward planning. The sense that we remain the same person despite temporal change is felt at an emotional level and may lead to ideas of having a "true" or essential self. Bridges (2001) saw this stability of the self as a problem. He said people need to reflectively embrace cathartic experience to bring about self-change, and he advised people in transitional situations to let go of their subjective realities and identities so as to create more effective worldviews and selves. Transitions take longer than change, he said, because the former involves the development of "a replacement reality and a new self" ( p. 3). Once we have said goodbye to our old self, we will be in a neutral zone, a condition similar to grieving, while the new self is being constructed. He cautioned, "The most significant transitions involve a time in hell" (Bridges, 1980, p. 156).

In summation, reflective individuals will gain new experiential learning soon after significant events. Further reflection will occur when such experiential learning is remembered, and this may lead to new interpretations. The emphasis of holistic portfolio PLAR is on cataloguing all major life experiences with concomitant learning. The portfolio PLAR facilitator acts as a guide and teacher, opening the student to new possible interpretations. If the new learning is of such magnitude and direction as to involve substantively discarding an old self and the assumption of a new self, emotional catharsis could result. There is a major difference between recognizing the possibility of emotional catharsis and actively seeking it in a group setting. A justification for such a practice applied to aboriginal people is found in a particular conceptualization of colonialism that we examine next.

\section{Historic Trauma: The Need for Aboriginal Identity Reconstruction}

From an historic trauma perspective, the military, economic, and cultural conquest of people aboriginal to the American continents was a form of genocide, and their descendants continue to face the traumatic effects of that genocide in a manner similar to the intergenerational trauma faced by descendants of Holocaust victims (Brave Heart, 2003; Wesley-Esquimaux \& Smolewski, 2004). Brave Heart (2003) catalogued a constellation of resultant symptoms experienced by aboriginal people, including depression, self-destructive behaviour, suicidal thoughts and gestures, anxiety, low self-esteem, anger, difficulty recognizing and expressing emotions, and substance abuse.

Wesley-Esquimaux and Smolewski (2004) agreed that this historic trauma is passed on intergenerationally, continuously acted out and recreated in contemporary aboriginal culture. Brave Heart (2003) used Lakota prayer and purification ceremonies to treat historic trauma in traditional retreat-like settings in which historically traumatic memories were "awakened" by using audiovisual materials through which participants "relived" genocidal 
massacres. She explained, "This is done in order to provide opportunities for cognitive integration of the trauma as well as the affective cathartic working-through necessary for healing" (p. 11).

The approach used by Brave Heart is based on an assumption that indigenous peoples have a common historical trauma and that cathartic experience is needed to stimulate identity construction. Other understandings are possible. The assumption of common historical trauma ignores differences in the relationships aboriginal peoples had with colonizers. For example, the Cree, as "middle men" for the Hudson Bay Company, had a different relationship with their colonizers than did the Blackfeet, who were given smallpox-infected blankets during wars with the US American military (Ewers, 1958). Further, the historic trauma approach ignores research indicating that aboriginal people may have lower rates of trauma than do non-aboriginal people despite being in circumstances that could be trauma-producing (Manson et al., 2002; Waldram, 2004).

An application of PLAR that assumes a need to remake the self-identities of aboriginal people is grounded in a historic trauma worldview. A suggestion that aboriginal people need to "reclaim their indigenous identity" implies a template outlining such an identity, resulting in a process whereby the effects of colonization on the aboriginal self must be dealt with by cathartic means, with a subsequent identity offered to participants. The assumption that all aboriginal people have a need to undergo this process is controversial.

\section{Perceptions of Staff of Aboriginal or Holistic PLAR Workshops}

As we have seen, the historic trauma model allows for the construction of a paradigm wherein the identities or selves of aboriginal people are understood to have been damaged by colonialism and that a modified form of portfolio PLAR could be used to repair that damage. Users of such a model would be expected to invite emotional catharsis in an effort to identify aspects of identity requiring transformative change, and they would then suggest replacement identities as needed. Concerns voiced by Northlands College classroom instructors, student advisors, and administrative staff who completed aboriginal holistic portfolio PLAR training in 2008 are consistent with this model. Five such trainees said they felt inadequately prepared to handle emotional catharsis flowing from the recollection of past traumatic experiences, and they expressed dismay that the facilitator appeared to seek such catharsis in the group setting. One participant said he did not feel believed when he claimed to have no trauma to disclose. A second said he felt uncomfortable when a coworker disclosed potentially embarrassing sexual details amid tears and recriminations. He lamented, "She [the group facilitator] seemed more sinister when she singled out the weaker, more vulnerable members of our group and encouraged or caused them to cry - the harder and longer the better." Participants also questioned the course content, with one stating,

Our provincial Department of Higher Education and Manpower has no more business teaching Native Spirituality - with the intent of conversion - than it has 
teaching Tibetan Buddhism.... Imagine what towering indignation would have been engendered had (the PLAR instructor) been a Catholic and she had asked us to burn incense, to partake in Holy Sacraments, to confess our sins, and tied problem-solving to the four points of the Cross. (Interview, November 3, 2008)

The suggestion of an alternate identity or belief system could be perceived as an attempt at conversion. In a submission to Northlands College (summer 2007), the facilitator-trainer to this class explained:

Holistic portfolio development is a powerful process to help people identify and document the learning that they have acquired through life/work experiences....

Through holistic portfolio development, learners can begin to identify how ethnostress has impacted them and begin a process to reclaim their indigenous identity.

According to this facilitator-trainer, the recollection of painful experiences is necessary "because that is where our greatest learning comes from," and "emotional stuff keeps them (aboriginal people) from reclaiming spirit” (personal interview, January 9, 2009). This view was supported by Hill (2004):

The learners are helped to unburden themselves of the painful memories and life experience that they carry. These sessions are particularly important as painful memories carry very intense feelings that cloud the learner's mind and prevent the learner from accurately assessing what she or he has learned. We believe that some of the most profound learning is contained within painful learning experiences. (p. 26)

Using a telephone interview format, I compared the perceptions of aboriginal holistic portfolio PLAR college trainees prior to 2008 with those of the 2008 group. Fifty-four individuals, including both Northlands College and non-college staff, completed six days of workshops from March 2004 to February 2007. An additional 11 staff received three days of training in 2008. An attempt was made to survey all of these participants in January and February 2009 using telephone contact information on file. Thirty-seven participants were contacted, and 30 agreed to be interviewed, including 16 college staff ( 8 from the 2008 group and 8 trained prior to 2007), and 14 non-college staff.

In answer to the open-ended question "What was the main idea behind the PLAR training you completed?" all of the Northlands College respondents who received their training prior to $2008(n=8)$ replied that it was one of assessment, developing self-knowledge, or giving credit for informal learning. Three of eight 2008 trainees but none of the earlier 
cohort said the main idea of PLAR was to teach "the aboriginal holistic model." A majority of the 2008 trainees (5) and those trained prior to 2008 (14) said their training included a focus on the learning needs of aboriginal students. Two of the 2008 trainees drew a distinction between teaching "the aboriginal holistic model" and including a focus on aboriginal learning needs.

Participants were asked, "Did the training you took include consideration of past events that may have been traumatic to the individual?" All eight 2008 trainees said their program included the exploration of such past traumatic events. Only eight of 22 respondents who took their training prior to 2008 said their training dealt with the issue of past trauma. A majority (5) of the 2008 college trainees but none of the earlier trainees (college and noncollege subsamples) said they would invite students to disclose past trauma in the group setting. Respondents were asked what they would do if a student became emotionally distraught while recalling past trauma, irrespective of whether disclosure was invited or not. Almost half of the college staff (7) said they would attempt to counsel such a student, roughly equally divided between 2008 and pre-2008 subsamples.

While this brief survey cannot be considered representative of training in aboriginal or holistic portfolio PLAR outside the specific region studied, it does illustrate a spectrum of understandings by trainees. In its emphasis on inviting disclosure of past trauma in a group setting, and in its subsequent teaching of "the aboriginal holistic model" as part of identity construction, the approach learned by the 2008 class most closely resembled the historic trauma model. While the possibility of traumatic memories surfacing was part of earlier versions of this training, none of those trainees would invite students to disclose such memories.

Educational institutions have always been in the business of identity construction, with students interpreting themselves, in part, on the basis of academic success or failure. PLAR affords an opportunity for a holistic self-examination and reinterpretation combining the awarding of credit for verified past learning with a process of self-development. This includes consideration of reinterpretive possibilities that would enhance career development, broadly defined to include meaningful work, learning, and community and leisure activities. It is well within the mandate of educators and counsellors to assist students in the development of their personal portfolios for the purpose of increasing self-understanding, and such understanding will reflect the cultures with which the person self-identifies. When dealing with self-change, however, the boundaries between the mandates of institutions and the expertise of professionals within those institutions may become blurred.

Educators in the classroom setting necessarily generalize when teaching historical or cultural concepts, but such generalizations may lead to inappropriate assumptions when dealing with individual identity. The code of ethics of the Canadian Psychological Association states, "Each person should be treated primarily as a person or an end in him/herself, not as an object or a means to an end" (2000, p. 8). The notion of a template for identity development based on cultural generalizations may be in conflict with this principle. The suggestion that those trained in a particular approach to PLAR portfolio development who are 
not psychologists and who have not received training in dealing with post-traumatic stress might invite traumatic disclosure in a group setting is of further concern.

As we have seen, the practice of inviting individuals to share personal trauma was not common to all groups of college trainees in our sample. While a majority of the 2008 trainees said they would invite traumatic disclosure from college students while assisting them to develop their portfolios, none of the earlier cohort would do so. Concomitantly, trainees from both cohorts considered themselves ill-prepared to deal with possible instances of resultant emotional catharsis. The expectation that PLAR portfolio facilitators who are not trained in therapeutic methods to reduce unresolved psychological trauma should nonetheless invite such disclosure carries an assumption that the expression of trauma is in itself therapeutic. While health benefits have been noted in individual, often written, disclosure of traumatic events (Greenberg \& Stone, 1992; Pantchenko, Lawson, \& Joyce, 2003), the participants in such studies are primarily healthy individuals. A study of 74 women with a history of sexual assault victimization (Kearns, Edwards, Calhoun, \& Bidycz, 2010) found improvement in mood immediately after written disclosure, but no change as compared to a group of controls who did not disclose after a one-month follow-up. A study of 61 women who had been sexually abused as children and were interviewed biweekly for a 12-week period revealed no psychological or physical health benefits associated with written disclosure and deterioration in the health of those who disclosed solely in visual art form (Baten, Follette, Hall, \& Palm, 2002). The potential danger of inviting such disclosure by untrained individuals without adequate therapeutic support was illustrated by Robertson (2006), who reported the case of an aboriginal client whose symptoms of Residential School Syndrome appeared full-blown after he was encouraged by his lawyer to recount the details of sexual and physical abuse, and these newly expressed symptoms were followed by the loss of employment and family. Residential School Syndrome has been defined as exhibiting similar symptoms to those attributed to historic trauma, but the condition is thought to be triggered by conditions frequently found in Indian residential schools (Brasfield, 2001; Robertson, 2006). In this case, the client had been encouraged to recount his trauma in written form, thereby replicating the method commonly used in those studies demonstrating a benefit to disclosure, but he experienced additional pressure by virtue of his decision to proceed with legal action.

There is much research supporting the view that disclosure as part of a recognized psychological intervention is effective (Devilly \& Spence, 1999; Gerrity \& Solomon, 2002; Wilson, Becker, \& Tinker, 1995). In one study, 670 women were screened for sexual victimization, with 65 meeting the twin criteria of reported sexual coercion or rape victimization and high current psychological distress (Anderson, Guarardo, Luthra, \& Edwards, 2010). Twentyeight selected randomly were divided into two groups: One group participated in four emotion-focused therapeutic sessions, while the "controls" reported four times for an assessment of their psychological functioning. Initially, no differences were observed between the two groups of disclosers; however, a three month follow-up revealed the treatment group as having significant reductions in interpersonal stress, including hostility, dependency, and avoidance symptoms. 
In summation, individuals with essentially intact or healthy selves may recount painful memories and experience group validation effects; however, disclosure of unresolved trauma outside a therapeutic setting may be harmful. Any attempt to move PLAR from an instrument of assessment with concomitant self-growth to an instrument of therapy puts the psychological health of some individuals at risk. Recognized psychological interventions outside the PLAR setting could be available for those who need to disclose unresolved trauma.

In a second ethical challenge, some of the 2008 trainees objected that they were either proselytized or expected to proselytize others into a religion or quasi-religion called native spirituality. Many aboriginal writers have claimed that native spirituality is not a religion (McCormick, 1996; Mehl-Madrona, 2003; Mussel, 2005); however, the distinction between what constitutes a religion and what might constitute spirituality without religion is not always clear. As used by the 2008 trainees, the term religion appears to refer to a codified belief set that is held to be absolutely true, coupled with associated practices or ceremonies. It is instructive that none of the 2004-2007 trainees raised this ethical concern, and their training was entitled "An Aboriginal Perspective on PLAR." Had their training been called "The Aboriginal Perspective on PLAR," people of aboriginal ancestry who did not share this perspective in some respects might have objected. The largest number of trainees within the 2008 cohort (but none of the earlier trainees) said the main idea of this application of portfolio PLAR was to learn "The Aboriginal Holistic Model." The existence of such a singular model might appear axiomatic to someone who carries a template of what constitutes a healthy aboriginal identity, but as Berry (2002) has pointed out, the universe of functional and satisfied aboriginal people encompasses a spectrum of possible identities and worldviews.

The appearance of delivering what might appear to be a revealed or absolutist truth would be avoided by generating alternatives and inviting individuals to develop their own truths encompassing their own prior learning. The notion that beliefs are relativistic, varying according to context, and that individualized personal knowledge with different circumstances demands different responses, is found in both aboriginal and western cultures (Korhonen, 2002). The Northlands College trainee quoted earlier perceived the medicine wheel to be a religious symbol of native spirituality; however, it is also possible to view it as a concept that may be applied relative to the prior learning of the individual.

All societies need a mechanism for combining disparate information into a "big picture" or "whole," and in aboriginal cultures this is often presented in the form of a medicine wheel or circle. A medicine wheel restricted to physical, mental, emotional, and spiritual dimensions may be constraining for some individuals. Roberts, Harper, Bull, and HeidemanProvost (1998) acknowledged a wide variety of medicine wheels within aboriginal cultures, with none having a claim to being the authentic or primal one. In an undergraduate class on aboriginal health, students construct their own medicine wheels containing those elements considered by the individual as necessary and sufficient to represent their personal idea of holism. 
Other themes within a non-religious native spirituality may be referenced without reifying a particular set of practices and beliefs. Berry (1999) found that having a relationship with the land that included hunting, trapping, fishing, and berry picking was generally important to the spirits of Inuit, Indian, and Métis peoples. This can be a useful concept without prescribing a particular way of interacting spiritually with the land. In my own private practice in counselling psychology, I have sometimes suggested that clients consider spending time on a trap line, but what they do on the trap line is individualized-they must find their own best way of reflecting and communing with nature.

\section{Discussion and Conclusions}

This paper has given voice to aboriginal holistic portfolio PLAR trainees who objected to certain aspects of their training on ethical grounds. While our historical scan of Northlands College PLAR trainees from previous years suggested that the experience of the 2008 group may have been anomalous in some ways, their perspective reminds us of the importance of addressing ethical issues as a guide to future practice. We have seen how a historic trauma perspective coupled with notions of an essentialist aboriginal self may lead to an expectation that all aboriginal people suffer unresolved trauma that must be disclosed so as to permit the implementation of replacement identities. While I do not suggest that this represents the thrust of all or even a majority of holistic portfolio PLAR training, the existence of this view emanating from even one class demonstrates the need for ethical principles to guide us in implementing this self-development process.

First, the right of individuals to develop their own personal cultures should be respected. While the process of reflecting on prior experience may lead to the construction of new knowledge with new concomitant understandings of one's self, those understandings should be individualized without pressure to conform to pre-existent models. Suggestions that a person is more or less aboriginal, dependent on the choices made with respect to his or her personal culture, should be avoided.

Limits to professional competency need acknowledgement. The facilitator trainees in this study included classroom instructors who could incorporate aspects of PLAR portfolio development into existent curricula. Such classroom instructors trained in portfolio PLAR may be quite competent in teaching students how to construct portfolios, and classroom discussion identifying skills and knowledge evidenced from student experience can be valuable. Classroom instructors should not be expected to counsel students with respect to individual identity construction, nor should they invite disclosure of unresolved trauma. Students who exhibit difficulty interpreting experiences, whose experiences include private or confidential matters, or who appear to be in personal crisis should be referred to a counsellor.

Counsellor expertise will vary, and each has a professional duty to recognize his or her personal limit of competence, re-referring clients whose needs are beyond the counsellor's level of training. Counselling staff with skills in vocational counselling, supportive counselling, 
and crisis intervention can extend the work of instructors using aspects of PLAR portfolio development in the classroom, but they may not be competent in dealing with psychological distress. Counsellors should not attempt to deal with symptoms of post-traumatic stress, personality, or self-reconstruction, except on a crisis intervention basis, unless they have professional training in these areas. Internal and external professional resources that may be required by students need to be identified.

In summation, PLAR portfolio development has the potential to assist students to define themselves in empowering ways. This potential may be particularly relevant to individuals from colonized populations who have experienced disempowering histories. Educational institutions engaging in this form of portfolio development would be advised to develop protocols ensuring a team approach with defined levels of competency and adequate referral mechanisms. 


\section{References}

Amichand, S., Ireland, M., Orynik, K., Potter, J., \& Van Kleef, J. (2007). Quality assurance in PLAR: A guide for institutions (Vol. II). Canadian Council on Learning.

Anderson, T., Guarardo, J. F., Luthra, R., \& Edwards, K. M. (2010). Effects of clinicianassisted emotional disclosure for sexual assault survivors: A pilot sudy. Journal of Interpersonal Violence, 25(6), 1113-1131.

Baten, S. V., Follette, V. M., Hall, M. L. R., \& Palm, K. M. (2002). Physical and psychological effects of written disclosure among sexual abuse survivors. Behavior Therapy, 33(1), 107-122.

Berry, J. W. (1999). Aboriginal cultural identity. Canadian Journal of Native Studies, 19(1), $1-36$.

Berry, J. W. (2002). Conceptual approaches to acculturation. In K. M. Chun, P. B. Organista, \& G. Marin (Eds.), Acculturation: Advances in theory, measurement, and applied research (pp. 17-38). Washington, DC: American Psychological Association.

Brasfield, C. R. (2001). Residential school syndrome. B.C. Medical Journal, 43(2), 78-81.

Brave Heart, M. Y. (2003). The historical trauma response among natives and its relationship with substance abuse: A Lakota illustration. Journal of Psychoactive Drugs, 35(1), 7-13.

Bridges, W. (1980). Transitions: Making sense of life's changes. Reading, CA: AddisonWesley Publishing.

Bridges, W. (2001). The way of transition: Embracing life's most difficult moments. Cambridge, MA: Da Capo.

Canadian Psychological Association (2000). Canadian code of ethics for psychologists (3rd ed.). Ottawa, ON.

Conrad, D. (2008). Building knowledge through portfolio learning in prior learning assessment and recognition. Quarterly Review of Distance Education, 9(2), 139-151.

Devilly, G. J., \& Spence, S. H. (1999). The relative efficacy and treatment distress of EMDR and a cognitive-behavior trauma treatment protocol in the amelioration of posttraumatic stress disorder. Journal of Anxiety Disorders 13(1), 131-157.

Ewers, J. C. (1958). The Blackfeet. Norman, OK: University of Oklahoma Press.

Gerrity, E. T., \& Solomon, S. D. (2002). The treatment of PTSD and related stress disorders: Current research and clinical knowledge. In A. J. Marsella, M. J. Friedman, E. T. Gerrity \& R. M. Scurfield (Eds.), Ethnocultural aspects of posttraumatic stress dis- 
order: Issues, research, and cinical applications (pp. 87-104). Washington, DC: American Psychological Association.

Greenberg, M. A., \& Stone, A. A. (1992). Emotional disclosure about trauma and its relation to health: Effects of previous disclosure and trauma severity. Journal of Personality and Social Psychology, 63(1), 75-84.

Hill, D. (2004). Learning as transformation: An aboriginal perspective on prior learning assessment and portfolio development. Hagersville, ON: First Nations Technical Institute.

Kearns, M., Edwards, K., Calhoun, K., \& Bidycz, C. (2010). Disclosure of sexual victimization: The effects of Pennebaker's emotional disclosure paradigm on physical and psychological distress. Journal of Trauma and Dissassociation, 11(2), 193-209.

Knowles, M. (1970). The modern practice of adult education: Andragogy versus pedagogy. New York: Association Press.

Korhonen, M.-L. (2002). Inuit clients and the effective helper: An investigation of culturally sensitive counselling. Durham, UK: University of Durham.

Manson, S., Beals, J., O’Nell, T., Piasecki, J., Bechtold, D., Keane, E., \& Jones, M. (2002). Wounded spirits, ailing hearts: PTSD and related disorders among American Indians. In A. J. Marsella, M. J. Friedman, E. T. Gerrity \& R. M. Scurfield (Eds.), Ethnocultural aspects of postraumatic stress disorder: Issues, research, and clinical applications (pp. 255-284). Washington, DC: American Psychological Association.

McCormick, R. (1996). Culturally appropriate means and ends of counselling as described by the First Nations people of British Columbia. International Journal for the Advancement of Counselling, 18, 163-172.

Mehl-Madrona, L. (2003). Coyote healing: Miracles in native medicine. Rochester, VT: Bear \& Co.

Morrissey, M., \& Myers, D. (2008). Achieving our potential: An action plan for prior learning assessment and recognition (PLAR) in Canada. Halifax, NS: Prior Learning Assessment Centre.

Mussel, W. J. (2005). Warrior-caregivers: Understanding the challenges and healing of First Nations men. Ottawa, ON: Aboriginal Healing Foundation.

Pantchenko, T., Lawson, M., \& Joyce, M. R. (2003). Verbal and non-verbal disclosure of recalled negative experiences: Relation to well-being. Psychology and Psychotherapy: Theory, Research and Practice, 76(3), 251-265.

Roberts, R. L., Harper, R., Bull, T.-E., \& Heideman-Provost, L. M. (1998). The Native Amer- 
ican medicine wheel and individual psychology: Common themes. Journal of Individual Psychology, 54(1), 135-146.

Robertson, L. H. (2006). The residential school experience: Syndrome or historic trauma. Pimatisiwin: A Journal of Aboriginal and Indigenous Community Health, 4(1), $1-28$.

Robertson, L. H. (2010). Mapping the self with units of culture. Psychology, 1(3), 185-193.

Van Kleef, J. (2007). Strengthening PLAR: Integrating theory and practice in post-secondary education. Canadian Journal of Applied Research in Learning, 1(2). Retrieved from http://www.ccl-cca.ca/ccl/Reports/Journal/JARLSept2007_Issue2_Art5. html

Waldram, J. B. (2004). Revenge of the Windigo: The construction of the mind and mental health of North American aboriginal peoples. Toronto: University of Toronto Press.

Wesley-Esquimaux, C. C., \& Smolewski, M. (2004). Historic trauma and aboriginal healing. Ottawa, ON: Aboriginal Healing Foundation.

Wilson, S. A., Becker, L. A., \& Tinker, R. H. (1995). Eye movement desensitization and reprocessing (EMDR) treatment for psychologically traumatized individuals. Journal of Consulting and Clinical Psychology, 63(6), 928-937.

\section{Athabasca University $\mathbf{I}$}

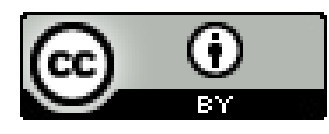

